DOI 10.37882/2223-2982.2021.11-2.31

\title{
ИССЛЕДОВАНИЕ МУЛЬТИМОДАЛЬНОГО ДИСКУРСА В КИТАЕ
}

\section{RESEARCH ON MULTIMODAL DISCOURSE IN CHINA}

Jiang Shan

Summary: The article examines the characteristics of multimodal discourse in general, the manifestations of multimodality in ancient China, and also provides an overview and analysis of research on this topic in modern China.

The object is the analysis of the concept of «xiang» (Xiàng, 象) and the research directions of multimodal discourse in China.

The purpose is to find out how the concept of multimodal discourse manifests itself in ancient China and to analyze the results of research conducted by Chinese scientists on this topic.

The result is obtained by the scientific methods: analysis, synthesis and explanation. On the basis of scientific research and a combination of these methods, it can be concluded that, multimodality is a natural phenomenon in the communicative process. The concept of «xiang» (Xiàng, 象) includes visual, auditory, and other modalities. Based on studying various documents, four main directions in the study of multimodal discourse were identified and the contribution of modern Chinese linguists to the theory and practice of multimodal discourse was evaluated.

Keywords: multimodal discourse, ancient China, the concept of «xiang» (Xiàng, 象), research directions.

\section{Цзян Шань \\ Аспирант, Российский университет дружбы народов shan699@yandex.ru}

Аннотация: В данной работе рассматриваются характеристики мультимодального дискурса в целом, проявления мультимодальности в древнем Китае, а также представляется обзор и анализ исследований по данной теме в современном Китае. Объектом исследования выступают анализ концепции «сян» (Xiàng,象) и направление исследования мультимодального дискурса в Китае. Цель исследования - узнать, как проявляется концепция мультимодального дискурса в древнем Китае и проанализировать результаты исследований, проведённых китайскими учеными по данной теме. Результат работы получен методами научного познания: анализа, синтеза и объяснения. По результатам научных исследований и сочетаний указанных методов пришел вывод 0 том, что мультимодальность - естественный феномен в коммуникативном процессе. Концепция «сян» (Xiàng,象) включает в себя визуальную, слуховую и др. модальности. На примерах взглядов китайских ученых и результатов их исследований были определены четыре основных направления в исследовании мультимодального дискурса и оценен вклад современных китайских лингвистов в теорию и практику мультимодального дискурса.

Ключевые слова: мультимодальный дискурс, древний Китай, концепция «сян» (Xiàng, 象), направления исследований.

Г. Кресса и Т. Ван Леувена является труд «Чтение изображений: грамматика визуального дизайна», опубликованная в 1996 году [9, с 1]. В нём Ван Леувен рассматривает мультимодальность как комбинацию различных символических модусов в коммуникационных событиях (в речи и музыке) [17, с 301]. Г. Кресс поддерживает эту точку зрения и добавляет, что мультимодальный подход может представить все модусы как одну область [16, c 35-50].

Свой вклад в развитие теории мультимодальности внесли и китайские лингвисты. Так, Чжу Юншэн предлагает два подхода определения мультимодального дискурса. Первый подход, получивший широкое распространение в академических кругах Китая, предлагает разграничивать дискурс в зависимости от количества задействованных в нем модальных составляющих. Если используется только одна модальность, то такой дискурс можно назвать мономодальностью, а при наличии двух или более модальностей дискурс становится мультимодальным. Второй подход предлагает определять количество используемых семиотических систем. Некоторые виды дискурса могут включать только один из видов модальности, но при этом задействовать более 
одной семиотической системы. Например, в комиксы включена только визуальная модальность, однако они содержат как текст, так и изображения [14, с 82-85].

Концепция мультимодальности появилась в Китае еще в древности. В период до династии Цинь И. Чжуань в работе «Древние философские и этические труды» ввел понятие «сян» (Xiàng, 象) - образ между речью и знанием высказывания. Его также рассматривают как метод классификации и анализа вещей, используемый древними людьми, а также как средство и метод познания мира.

Понятие «сян» фактически играет роль установления связи между физическим и эмпирическим миром [1, с 3]. Известны такие высказывания, как: «подняв чело вверх, постигать небесные явления»; «опуская лицо вниз, постигнуть законы земли»; «гадание основано на аномальных изменениях в собственном теле и окружающей среде, чтобы высказывать суждения о ситуации и предсказывать результаты»; «в словах совершенного мудреца проявляется искренность»; «совершенный мудрец использовал метод создания «сян» чтобы полностью выразить свои мысли» и т. д. Приведенные цитаты отражают теорию происхождения языка согласно понятию «сян», а также отображают понимание мультимодальных характеристик языка древними китайскими философами. Известный писатель династии Цзинь сказал: «Чтобы заявить правду о вещах, наиболее эффективным является язык, а чтобы сохранить образ вещи - картина». Цао Чжи, известный писатель периода троецарствия, считал, что изображения могут быть более наставительными, чем слова.

Во времена ранней династии Тан, известный художник Пей Сяоюань, в работе «Запись живописей Чжэнгуань», подчеркнул важную роль изображений. Чжан Яньюань, известный художник того времени, также считал, что изображения более эффективны, чем слова, при необходимости описания исторических событий, внешности персонажей, обычаев и т.д. В своей работе он написал: «Биографии могут использоваться только для повествования, но не для отображения образа вещей. Стихи могут описывать вещи только словами, но они не могут показать первоначальный внешний вид вещей. Только образы могут выражать как коннотацию, так и внешний вид вещей».

Китайский ученый Чжэн Цяо, живший во времена династии Сун, считал, что само по себе письмо, без использования средств наглядности, может превратить обучение в фиктивное обучение. Он полагал, что изображение и язык гармонично сосуществуют и дополняют друг друга.

Чжэн Чжэньдуо, известный писатель и историк китайской литературы прошлого века, говорил: «Без изо- бражений трудно понять всё - от природы исторических личностей, событий, явлений до архитектуры, искусства, предметов повседневного обихода, формы одежды. Благодаря изображениям легче понять содержание и значение, которые автор вкладывал в свое произведение» [13, c 498].

Приведенные выше цитаты доказывают, что использование мультимодальности было очень распространено в Древнем Китае. Большинство учёных того времени предпочитали наглядную форму - изображения, для выражения определенных значений. Многие из них также подчеркивали необходимость использования изображений для проявления эмоций. Использование текста, музыки, изображений и других мощных форм передачи эмоций наиболее частотны в художественном и литературном творчестве.

В современном Китае исследование мультимодального дискурса берёт начало с работы «Социально-семиотический анализ мультимодального дискурса» [2, с 1-7]. В этой статье подробно рассматривается концепция «визуальной грамматики» Г. Кресса и Ван Леувена. Еще одна знаковая статья этого времени - «Мультимодальность в исследованиях социальной семиотики» Ху Чжуанлиня, известный китайский лингвист, пионер в области лингвистики в Китае, рассматривает различия модальности и медиа с точки зрения социальной семиотики [6, с 3]. Чжу Юншэн - профессор института иностранных языков университета Фудань, выделил четыре вопроса, тесно связанных с анализом мультимодального дискурса:

1. появление мультимодального дискурса,

2. определение мультимодального дискурса,

3. характеристики и теоретические основы мультимодального дискурса,

4. содержание, метод и значение мультимодального дискурса.

Чжан Дэлу - выдающийся лингвист, профессор Университета Тунцзи, попытался создать комплексную структуру для мультимодального дискурса на основе теории системно-функциональной лингвистики. Он заметил, что мультимодальный дискурс можно изучать на нескольких уровнях, таких как культура, контекст, значение дискурса, грамматика и форма. [10, с 24-29].

В Китае исследование мультимодального дискурса ведется наравне с международными исследованиями. Результаты данных исследований могут быть разделены на следующие четыре направления:

\section{1. Мультимодальный Аискурс на теоретической основе системно-функчиональной лингвистики и сочиосемиотики}

Отличия от мультимодального дискурса системно- 
функциональной лингвистики определены в соответствии с теорией семиотики и системно-функциональной лингвистики М. Халлидея и социальной семиотики, предложенной Г. Крессом и Т. Ван Леувеном. В Китае ученые, занимающиеся исследованием мультимодального дискурса, различают понятия системно-функциональной лингвистики и социальной семиотики не так строго, как это принято международным сообществом. Подход китайских учёных к этому вопросу строится на утверждении, что из системно-функциональной лингвистики развивается социальная семиотика.

Лингвисты Китая занимаются развитием основных концепций и теорий, связанных с мультимодальностью, с периода первого появления этого понятия и до наших дней. Основное направление деятельности заключается в определении сходства и различий между концепцией «модуса» и «модальности», изучении мультимодального дискурса на теоретической основе семиотики, а также в исследовании построения мультимодальной грамматики.

Чжан Дэлу и Чжан Цзинтянь в своем научном труде «Исследование конструкции мультимодальной грамматики» постарались дать ответы на следующие вопросы:

- Нужна ли универсальная грамматика для всех знаковых систем;

- Насколько целесообразен подход к разработке индивидуальной грамматики для каждой знаковой системы.

По мнению данных лингвистов, доминирующими факторами при построении мультимодальной грамматики являются уровень знаковой системы, тип знаков и размерность знаков [7, с 38-43]. Проведенные исследования по данным вопросам основываются на визуальной грамматике в социальной семиотике и предлагают модель мультимодального анализа, подходящую для конкретных жанров. Результаты исследования выявили две системы символов текста и изображений и дали оценку их роли в создании семантики в конкретных жанрах. Ли Чжаньцзы и Лу Даньюн считают, что изучение мультимодального дискурса с точки зрения социальной семиотики началось в конце девяностых годов XX века и всегда было сосредоточено на способах распространения системно-функционального лингвистического подхода на все символические модусы [3, с 1-6].

\section{2. Анализ мультимодальных метафор}

Труды молодого учёного из Амстердама Чарльза Форсвилла, посвящённые социальной семиотике исследования в области когнитивной лингвистики, сочетают социальную семиотику, теорию метафор, теорию метонимии и теорию релевантности. Ч. Форсвилл считает, что метафора выражается не только в языке, но и в других знаковых модальностях. Им была предложена концепция мультимодальной метафоры, которая представляет собой метафорическое явление, в котором исходный домен и целевой домен представлены отдельно или двумя разными знаковыми моделями. Чаще всего одной из моделей является речевой знак. Задачи анализа мультимодальных метафор состоят в построении и интерпретации метафор и метонимии, а также в исследовании интерактивных отношений между ними в мультимодальном дискурсе [15, с 248].

В Китае анализ мультимодальных метафор начался поздно и находится в стадии активного развития. Основные результаты отражены в теоретической оценке и анализе конкретных случаев. В рамках теоретического обзора в своей статье «Новое развитие исследований концептуальных метафор - мультимодальная метафора» профессор Китайского Нефтяного Университета (Пекин) Чжао Сюфэн представила происхождение, развитие и перспективы исследования мультимодальных метафор [12, с 1-8]. Чжан Хуэй, председатель Китайской Ассоциации Когнитивной Лингвистики (China Cognitive Linguistics Association, (CLA) и Чжан Вэйвэй, преподаватель китайского нефтяного университета (кампус в восточном Китае), в своих трудах определяют основы метонимии мультимодальных метафор, взаимодействие метафор, координацию изображений и текстов, а также культурную природу мультимодальных метафор на примере рекламы [11, с 16-23].

\section{3. Мультимодальный анализ корпуса}

Мультимодальный анализ корпуса сочетает в себе методы анализа корпуса, системно-функциональную лингвистику и семиотику. Он направлен на проверку гипотезы о генерации смысла в области исследования мультимодального дискурса с помощью крупномасштабных методов корпуса. В настоящее время создан корпус для исследования мультимодального дискурса, например веб-сайтов, справочников, газет и журналов, который используется для обнаружения и изучения мультимодальных мыслей, а также наиболее частотных инструментов для создания мультимодальных корпусов - Anvil, Elan и т.д.

В Китае исследования мультимодального анализа корпуса еще находятся на теоретической стадии. Главным препятствием является недостаточное техническое обеспечение. Профессор Лю Цзянь и Ху Кайбао, директор Института корпусных исследований и приложений Шанхайского университета международных исследований (Shanghai International Studies University Institute of Corpus Studies and Applications, ICSA), утверждают, что, при надлежащем развитии техники, возможно создание корпуса мультимодальной интерпретации. В этом случае аудио и видеоданные могут быть напрямую сег- 
ментированы и аннотированы, благодаря чему мультимодальную информацию корпуса удастся сохранить наиболее полно. Такой вид хранения данных и последующее их воспроизведение позволит использовать корпус интерпретации текста эффективнее, чем это происходит в настоящее время. В результате анализа состояния мультимодальных корпусов в Китае и за рубежом, а также оценки существующих исследований, Лю Цзянь и Ху Кайбао предприняли попытку создания технологии мультимодальной интерпретации, включающей эффективный сбор данных и высокое качество корпуса, сегментацию и транслитерацию мультимодального корпуса, а также модель многоуровневой маркировки (включая маркировку невербальных факторов, таких как паралингвальные явления), оценку надежности маркировки и т. д. [4, с 77-83].

\section{4. Мультимодальный интерактивный анализ}

Теоретической основой мультимодального интерактивного анализа является интерактивная социолингвистика и опосредованный дискурс, а также некоторые особенности социальной семиотики. В то же время речь рассматривается как социальное поведение, а интерактивный процесс считается процессом совместного участия. Данный тип анализа фокусируется на том, каким образом участники общения используют разные знаковые модальности для достижения целей социальной деятельности, и какова роль идентичности в интерактивном процессе.

В Китае среди всех опубликованных статьей, которые касаются темы мультимодального интерактивного анализа, можно заметить, что только Чжан Дэлу и Ван Чжэн, доктора филологических наук Университета Тунцзи, представили основные теории и методы данного типа. В рамках проекта Китайского Национального фонда социальных наук «Исследование модели обучения разносторонних способностей студентов, изучающих иностранные языки», были рассмотрены характеристики этого типа анализа, его достоинства и недостатки, а также предложена собственная комплексная структура мультимодального интерактивного анализа. Согласно ему, в отличие от традиционного анализа дискурса, ориентированного на язык, мультимодальный интерактивный анализ относится к холистическому анализу, в котором опосредованное действие является основной единицей анализа, а язык считается лишь частью реального процесса коммуникации. Основная исследовательская структура мультимодального интерактивного анализа включает следующие аспекты:

1. действие (action) ;

2. уровни внимания / осведомленности (levels of attention/awareness) ;

3. средства (means);

4. сайт взаимодействия (site of engagement) ;

5. модальность (mode);

6. модальная плотность (modal density) ;

7. модальная конфигурация (modal configuration) ; 8. медиа (medium) .

Структура мультимодального интерактивного анализа прошла апробацию путем внедрения в уроки английского языка в колледже [8, с 54-60].

\section{Зак^ючение}

Концепция мультимодальности зародилась в Древнем Китае еще до периода правления династии Ци. Эмоции и чувства, которые писатели и поэты того времени передавали через поэзию и каллиграфию характеризуются понятием «сян». В настоящее время «сян» также можно заменить мультимодальностью. Однако сам термин «мультимодальность» появился лишь в первой четверти XX века, в связи с резко возросшим количеством изображений и других графических составляющих в журналах и рекламных постерах.

На современном этапе развития общества и науки в Китае все больше и больше ученых в области различных дисциплин начинают сочетать мультимодальность со своими собственными научными интересами, внося большой вклад в расширение теоретических знаний о мультимодальности. Результаты исследований такого рода симбиоза научных сфер имеют различия в методах, направлениях исследований и теоретических основах, но также иллюстрируют междисциплинарный характер мультимодальности и необходимость дальнейшего развития междисциплинарных мультимодальных исследований.

\section{ЛИТЕРАТУРА}

1. Ван Ханьдун Исследование взаимосвязи языковой философии и эстетики в эпоху до Цинь // Ухань: Вестник Хуачжунского университета науки и технологий, 2001. №.3. С 3.

2. Ли Чжаньцзы Социально-семиотический анализ мультимодального дискурса, // Нанкин: исследования иностранных языков, 2003. №.5. С 1-7

3. Ли Чжаньцзы, Лу Даньюн Мультимодальная семиотика: теоретические основы, подход к исследованию и перспективы развития // Нанкин: исследования иностранных языков, 2012. №.2. С 1-6

4. Лю Цзянь, Ху Кайбао Исследование о построении и применении корпуса мультимодальной интерпретации // Пекин: Иностранные языки в Китае, 2015. No.5. C $77-83$ 
5. Кибрик А.А. К вопросу о структуре мультиканального дискурса [Текст] / А.А. Кибрик, О.В. Федорова // Образы языка и зигзаги дискурса: сборник научных статей к 70-летию В.3. Демьянкова / В.В. Фещенко (ред.). - М.: Культурная революция, 2018. С. 181-182

6. Ху Чжуанлинь Мультимодальность в исследованиях социальной семиотики // Пекин: Обучение языкам и лингвистические исследования, 2007. №.1. С 3

7. Чжан Дэлу, Чжан Цзинтянь Исследование конструкции мультимодальной грамматики // Харбин: Журнал иностранных языков, 2012. №.3. С 38-43

8. Чжан Дэлу, Ван Чжэн Изучение структуры мультимодального интерактивного анализа // Пекин: Иностранные языки в Китае, 2016. №.2. ( $54-60$

9. Ч Чжан Дэлу Теория мультимодального дискурса и преподавание иностранных языков // Пекин: Издательство высшего образования, 2015. С 1.

10. Чжан Дэлу Анализ мультимодального дискурса и исследование теоретической структуры // Пекин: Иностранные языки в Китае, 2009. №.1. С 24-29

11. Чжан Хуэй, Чжан Вэйвэй Динамическое построение мультимодальной метонимии и метафоры в рекламном дискурсе // Нанкин: исследования иностранных языков, 2011. №.1. С 16-23

12. Чжао Сюфэн Новое развитие исследований концептуальных метафор — мультимодальная метафора // Нанкин: исследования иностранных языков, 2011. No.1. C 1-8

13. Чжэн Чжэньдуо Справочный атлас истории Китая // Шанхай: Шанхайская издательская компания,1951. С 498.

14. Чжу Юншэн Теоретические основы и методы исследования мультимодального дискурс-анализа // Харбин: Исследования иностранного языка. 2007. No.5. C 82-85

15. Forceville, C. Pictorial metaphor in advertising. // London: Routledge. 1996. P 248

16. Kress, G. Multimodal Discourse Analysis. // London: Routledge. 2011. P. 35-50.

17. Van Leeuwen T. Introducing Social Semiotics. // London:Routledge. 2005. P 301.

(c) Цзян Шань (shan699@yandex.ru).

Журнал «Современная наука: актуальные проблемы теории и практики»

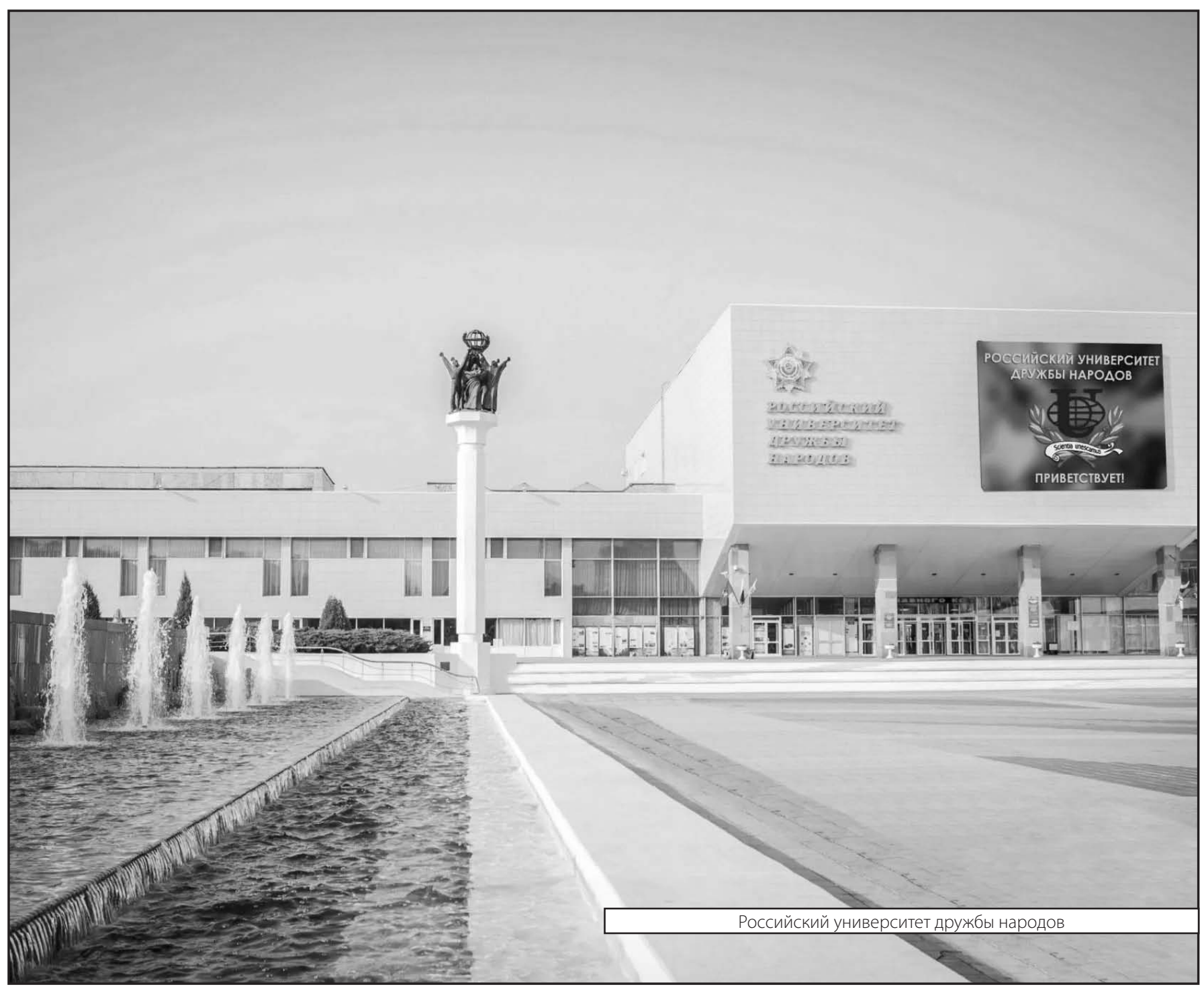

